\title{
THE UNITED STATES, MEXICO AND CANADA: EXPORTS \& IMPORTS FROM 2018 TO 2020, COVID-19'S YEAR
}

\author{
Rolando Pena-Sanchez, Texas A\&M International University, U.S.A.
}

\author{
dx.doi.org/10.18374/IJBR-20-4.3
}

\begin{abstract}
This article analyses the last three years of monthly monetary levels of exports and imports produced by the members of the new USMCA trade agreement signed by the United States, MÃ@xico and Canada, a treaty that replaced NAFTA. Although monthly data (January, 2018 - September, 2020) of these three countries indicate a significant correlation (Spearman's rho $p$-value $<0.01$ ) between their commercial balances, signaling the US as the country with the highest commercial activity, but the monthly \% growth rates of their exports and imports show a similar trade balance or not-significant difference in $\%$ growth rates (Kruskal-Wallis test p-values $>0.80$ ); in addition to the fact that even during the pandemic by Covid-19 these growth rates appear correlated (Spearman's rho $p$-value $<0.01$ ) in each one of the three countries, whose preliminary trade recoveries are presented.
\end{abstract}

Keywords: Exports, imports, trade balance, USMCA, Covid-19, Kruskal-Wallis test, Spearman's rho coefficient 